\title{
CRÍTICA E HISTORIOGRAFIA LITERÁRIA BRASILEIRAS ${ }^{1}$
}

\section{BRAZILIAN LITERARY CRITICISM AND HISTORIOGRAPHY}

\author{
Recebido: 14/05/2020 | Aprovado: 17/06/2020 | Publicado: 10/07/2020 \\ DOI: https://doi.org/10.18817/rlj.v4i1.2302
}

\author{
Roberto Acízelo de Souza ${ }^{2}$ \\ Orcid ID: https://orcid.org/0000-0003-0607-5911 \\ José Luís Jobim ${ }^{3}$ \\ Orcid ID: https://orcid.org/0000-0002-0271-6665
}

\begin{abstract}
Resumo: Os estudos literários brasileiros, depois de manifestações esparsas no período colonial, representadas pela atividade de academias literárias fundadas no século XVIII, só se expandiram efetivamente ao longo do século XIX. A produção literária nacional cresceu em quantidade e qualidade, assim como os estudos literários, que, por um lado, eram demandados por esta produção - a qual, afinal de contas, necessitava ser estudada e avaliada -, mas, por outro lado, estimulavam esta criatividade, ao estabelecerem como critério de valor o alinhamento da ficção, poesia e dramaturgia com a agenda nacionalista. Como resultado, de 1820 a 1880, os estudos literários no Brasil passaram por um período de expansão e diversificação. Se nos anos 1800 a educação literária foi conduzida no ensino de segundo grau, de 1930 em diante cursos de literatura em nível universitário começaram a estabelecer-se no Brasil. Neste artigo, faremos uma breve introdução à crítica e à historiografia literária brasileira, desde seus primórdios até o presente.
\end{abstract}

Palavras-chave: crítica literária brasileira, historiografia literária brasileira

\begin{abstract}
In Brazil literary studies, after scant manifestations in the colonial period, represented by the activity of literary academies founded in the 18th century only really expanded in the course of the 19th century. National literary production grew in quantity and quality, as did literary studies, which, on the one hand, were demanded by this production - that, after all, needed to be studied and evaluated -, but, on other hand, stimulated this creativity, as they established as a criterion of value the alignment of fiction, poetry and dramaturgy with the nationalist agenda. As a result, from the 1820s until the 1880s, literary studies in Brazil underwent a period of expansion and diversification. If in the 1800 s literary education was conducted at high-school level, from the 1930s onwards university courses in literatures began to be established in Brazil. In this paper we will provide a short introduction to Brazilian literary criticism and historiography from its very beginnings to the present time.
\end{abstract}

\section{Keywords: Brazilian literary criticism, Brazilian Literary historiography}

\footnotetext{
${ }^{1}$ Este artigo é uma tradução do texto 巴西文学批评及其历史沿革, publicado na Revista Foreign Language and Cultures (Revista de Línguas e Culturas Estrangeiras) no Volume 04 Edição 01 de Março de 2020.

2 Professor de Teoria da Literatura de 1977 a 2002 na Universidade Federal Fluminense, atualmente é professor titular de Literatura Brasileira da Universidade do Estado do Rio de Janeiro. Dedica-se à Literatura Brasileira e à Teoria da Literatura, com interesse especial na história e nos fundamentos conceituais dos estudos literários, bem como na historiografia da literatura brasileira. Mestre em Letras - Teoria da Literatura/UFRJ e doutor em Letras - Teoria da Literatura/ UFRJ, fez estudos de pós-doutorado na área de Literatura Brasileira/USP. E-mail: acizelo@bighost.com.br

${ }^{3}$ Mestre e doutor em Letras/UFRJ. Atualmente é Professor Titular da Universidade Federal Fluminense e Coordenador do Programa de Pós-Graduação em Estudos de Literatura (Nota 6, CAPES). Membro do Comitê de Pesquisa da International Comparative Literature Association (comitê administrativo da ICLA encarregado de avaliar novas propostas para comitês de pesquisa ad hoc da ICLA 2016-2019). E-mail: jjobim@id.uff.br
} 
No Brasil, os estudos literários, depois de manifestações esparsas no período colonial, representadas pela atividade das academias literárias fundadas no século XVIII, por curtos textos de alguns poetas - Cláudio Manuel da Costa (1729-1789), Basílio da Gama (1741-1795) e Silva Alvarenga (17490-1814) - e pelo ensino humanístico ministrado nas escolas (todas mantidas por ordens religiosas católicas), só se expandiram de fato no curso do século XIX. Contribuíram para essa expansão principalmente dois eventos políticos, com suas consequências no plano cultural: a transferência da sede da monarquia portuguesa para o Rio de Janeiro (1808) e a proclamação da independência nacional (1822). A partir daí, num ritmo que só faria crescer, o empenho no sentido de consolidar uma fisionomia própria para o Brasil no "concerto das nações civilizadas" (como se dizia então) conduziu, entre muitas implicações nos campos político, econômico e cultural, à concepção de um projeto estético-político de fundamentos românticos dedicado à construção de uma literatura propriamente brasileira, que, como tal, viesse a constituir um retrato de corpo inteiro da nação, representando sua natureza, história e sociedade. Cresce, assim, em quantidade e qualidade, a produção literária nacional, tendência acompanhada pelos estudos literários, que, por um lado, tornam-se demanda dessa produção - que, afinal, precisava ser estudada e avaliada -, mas, por outro, atuam como indutores dela, à medida em que erigem como critério de valor o alinhamento da ficção, da poesia e da dramaturgia com a agenda nacionalista. Assim, da década de 1820 à de 1880 os estudos literários no Brasil experimentam um período de expansão e diversificação.

No setor do ensino, prevalece uma atitude conservadora, que dá continuidade à tradição humanística do sistema escolar colonial, baseando a educação literária nas antigas disciplinas clássicas - retórica e poética -, quadro que só começou a mudar por volta dos anos 1870, quando essas disciplinas se veem substituídas por uma matéria moderna então introduzida nos currículos: história da literatura, particularmente da literatura brasileira. A necessidade de suprir materiais para uso escolar suscitou a produção de compêndios e manuais de 
retórica e poética, em geral obras esquemáticas e de alcance estritamente didático, orientadas por concepções clássicas, mas às vezes matizadas de algum traço de extração romântica, tributo mais ou menos inevitável à época em que foram produzidas. São exemplos dessa modalidade de obras, entre muitas outras, Lições de eloquência nacional (1846), de Lopes Gama (1793-1852), Elementos de retórica nacional (1869), de Junqueira Freire (1832-1855), Postilas de retórica e poética (1872), de Fernandes Pinheiro (1825-1876), Compêndio de retorica e poética (1879), de Costa Honorato (1838-1891), e Lições de retórica (1882), de Velho da Silva (1811-1901).

No âmbito da crítica, compreendida como estudo analítico de obras literárias específicas, proliferam ensaios, às vezes sobre obras do passado, mas principalmente sobre lançamentos então recentes, em geral veiculados em periódicos ecléticos, entre os quais Niterói (1836), Jornal de Debates Políticos e Literários (1837-1838), Minerva Brasiliense (1843-1845), O Guanabara (18491855), Revista Popular (1850-1869), A Atualidade (1859-1864). Nesse setor, destacam-se alguns nomes, como os de Dutra e Melo (1823-1846), Machado de Assis (1839-1908), Macedo Soares (1838-1905), Araripe Júnior (1848-1911).

Embora raras, registram-se também manifestações do que podemos chamar metacrítica, em textos, por exemplo, de Machado de Assis e Macedo Soares, bem como trabalhos críticos assinados por poetas e ficcionistas, dedicados à reflexão sobre seus próprios projetos literários pessoais ou à avaliação de obras alheias, sendo de destacar-se, nessa modalidade, contribuições de José de Alencar (1829-1877) e Álvares de Azevedo (1831-1852).

Quanto a estudos de natureza historiográfica, verifica-se o cultivo de vários gêneros.

Um deles é constituído pelas antologias ou florilégios, cuja finalidade originária, conforme definida poucos anos após a independência, era recolher a produção de poetas, sobretudo do período colonial, com o declarado objetivo de dar a conhecer aos próprios brasileiros as tradições poéticas do País, cuja qualidade, no dizer dos antologistas, depunha a favor da grandeza da pátria. Inaugura a série o Parnaso brasileiro (1829-1832), de Januário da Cunha Barbosa (1780-1846), ao qual se seguem outras duas obras de títulos homônimos, a primeira publicada em 1843 e a segunda em 1885, organizadas respectivamente 
por Pereira da Silva (1817-1898) e Melo Morais Filho (1844-1919), e ainda o Mosaico poético (1844), de Joaquim Norberto (1820-1891) e Emílio Adet (18181867), e o Florilégio da poesia brasileira (1850-1853), de Francisco Adolfo de Varnhagen (1816-1878), para ficarmos com as publicações mais destacadas nessa modalidade.

Aparecem também reuniões de biografias de escritores, casos do Plutarco brasileiro (1847) e Varões ilustres do Brasil nos tempos coloniais (1858), de Pereira da Silva, bem como do Panteon maranhense (1873-1875), de Antônio Henriques Leal (1828-1885), além de trabalho afim com essa modalidade, o Dicionário bibliográfico brasileiro (1883-1902), de Sacramento Blake (1827-1903).

$\mathrm{Na}$ área da historiografia literária, figuram também declarações de princípios visando à instauração de uma literatura autenticamente brasileira, sob a forma de manifestos que, empreendendo um balanço das letras dos tempos coloniais, exortam os escritores em atividade a aprofundarem os traços nacionais já supostamente embrionários naqueles séculos. Situam-se próximas desses ensaios as sínteses históricas da literatura brasileira, que, inventariando o passado, não deixam de fazer projeções sobre o futuro grandioso a que ela estaria destinada, pelo alcance pleno do que então se chamava caráter nacional. Como exemplos, podemos citar, na primeira modalidade, "Resumo da história literária do Brasil" (1826), de Ferdinand Denis (1798-1890), "Ensaio sobre a história da literatura brasileira" (1836), de Gonçalves de Magalhães (1811-1882), e "Da nacionalidade da literatura brasileira" (1843), de Santiago Nunes Ribeiro (circa 1820-1847); e, na segunda, "Bosquejo da história da poesia brasileira" (1841), de Joaquim Norberto, e "Formação da literatura brasileira" (1862), de Fernandes Pinheiro.

Mencionemos também a importante frente de pesquisas historiográficas constituída pela preparação de edições, em que se destacou Joaquim Norberto, cujo trabalho voltado para o estabelecimento de textos de poetas redundou em livros cuidadosamente editados, guarnecidos com notas e estudos críticobiográficos, dedicados às obras de Gonzaga (1744-1810), Silva Alvarenga (17491814), Alvarenga Peixoto (1742-1793), Gonçalves Dias (1823-1864), Álvares de Azevedo (1831-1852), Casimiro de Abreu (1839-1860) e Laurindo Rabelo (18261864), volumes vindos a público respectivamente nos anos de 1862, 1864, 1865, 1870, 1873, 1876 e 1877. 
Por fim, ainda no campo da historiografia, cabe destacar a produção de histórias da literatura brasileira, algumas de declarado propósito didático e outras de índole mais ensaística, porém todas destinadas a papel decisivo no que tange à institucionalização de uma ideia de literatura brasileira, dada sua inserção no sistema de ensino nacional. Pioneira nessa linhagem é a História da literatura brasileira, de Joaquim Norberto, que, contudo, permaneceu incompleta e dispersa, pois o autor abandonou o projeto, não tendo chegado a reunir em volume os capítulos que publicou na Revista Popular, de 1859 a 1862. Seguiram-se-lhe o Curso elementar de literatura nacional (1862), de Fernandes Pinheiro, O Brasil literário (1863), de Ferdinand Wolf (1796-1866), o Curso de literatura portuguesa e brasileira (1866-1873), de Sotero dos Reis (1800-1871), e, por fim, assinalando o ponto culminante do gênero no século XIX, a História da literatura brasileira (1888), de Sílvio Romero (1851-1914), obra que, pelo prestígio que logo granjearia, representa um marco no processo de consolidação da literatura brasileira - e de sua história - como disciplinas acadêmicas e instituições nacionais.

No geral, o cenário dos estudos literários no Brasil do Oitocentos foi fortemente determinado por uma perspectiva romântica e nacionalista, sintonizada, de resto, com o processo histórico de consolidação da independência do País. Mesmo no plano mais conservador, representado pelo sistema escolar, em que, como vimos, predominou uma visada universalista e baseada em valores clássicos, o nacionalismo não deixou de marcar posição, quer pela presença em títulos de manuais didáticos do sintomático adjetivo nacional - vejam-se os antes citados Lições de eloquência nacional e Elementos de retórica nacional (1869) -, quer pela introdução, a partir da década de 1870, da disciplina história da literatura brasileira nos currículos colegiais, com a correlativa exclusão de retórica e poética. Algumas poucas vozes, contudo, destoaram desse coro, casos de Abreu e Lima (17941869), na esquecida obra intitulada Bosquejo histórico, político e literário do Brasil (1839), Álvares de Azevedo, no longo e também esquecido estudo "Literatura e civilização em Portugal", escrito por volta de 1850, de publicação póstuma, e Machado de Assis, no seu ensaio famoso "Notícia da atual literatura brasileira: instinto de nacionalidade", publicado em 1873.

Assinale-se, por fim, ter sido bastante desigual a distribuição dessa produção pelo território do País, fortemente concentrada que foi no Rio de Janeiro, 
capital do império e depois da república, daí repercutindo nas demais regiões. Assim, em poucos outros centros floresceram os estudos literários com alguma intensidade, e em geral sem ressonância nacional: no norte, cabe citar São Luís, no Maranhão, e Recife, em Pernambuco, e, no sul, Porto Alegre, no Rio Grande do Sul. Um dos críticos literários mais importantes do século XIX, o antes mencionado Sílvio Romero, nascido na província de Sergipe (bem distante da capital e desses outros centros referidos), assim definiu a situação: "A função das províncias [...], do norte, sul, centro e oeste, é a de produzirem a variedade na unidade e fornecerem à Capital os seus melhores talentos" (Romero, 1907).

Esse quadro persistiu no século $X X$, chegando mesmo a agravar-se, com a concentração dos estudos literários no eixo Rio de Janeiro/São Paulo. Mais recentemente, não obstante melhor distribuição, com a expansão dos cursos universitários de letras - em particular de pós-graduação - em todos os estados, há ainda uma grande concentração da produção de crítica literária nas regiões sudeste e sul, onde se encontram os cursos universitários mais antigos e consolidados.

\section{2}

Tracemos agora um panorama do estado de coisas configurado no século $X X$, em seus diversos aspectos, começando pela questão do ensino.

Se no Oitocentos a educação literária se cingia ao nível médio, a partir da década de 1930 começam a ser implantados cursos universitários de letras no País. Até por volta dos anos 1960, só havia cursos de graduação, e reinava absoluto o ponto de vista historicista, exercendo papel central como subsídio bibliográfico os grandes tratados de história da literatura brasileira, cujo alto prestígio, como vimos, firmara-se ainda no século XIX, com a referida História da literatura brasileira, de Sílvio Romero. A dimensão teórica dos estudos literários, por sua vez, quase não era contemplada, o que explica a escassez de obras publicadas para apoiá-la. As poucas que surgiram, aliás, consistiam em manuais de retórica retardatários, quase inteiramente alheios às novas perspectivas já então definidas na área. É o caso de obras como Noções de estilística e literatura (1929), de Antenor Nascentes (18861972), Teoria da literatura (1935), de Estêvão Cruz (1902-1937), Princípios 
elementares de literatura (1935), de Augusto Magne (1887-1966), Teoria da literatura (1944), de Antônio Soares Amora (1917-1999), e Teoria literária (1965), de Hênio Tavares.

A partir da década de 1970, implantam-se cursos de pós-graduação mestrado e doutorado -, e correlativamente, em sintonia com tendência das grandes universidades europeias e norte-americanas, se fortalece o componente teórico dos estudos literários, publicando-se então manuais acadêmicos destinados a dar suporte ao ensino de nova disciplina introduzida nos currículos universitários brasileiros no início dos anos 1960 - a teoria da literatura -, matéria que, em carreira vertiginosa, em pouco tempo passou a fazer sombra às disciplinas de história literária tradicionais nas faculdades de letras brasileiras, literatura brasileira e literatura portuguesa. Além de manuais estrangeiros muito utilizados, como Teoria da literatura (1949), de René Wellek (1903-1995) e Austin Warren (18991986), e a obra homônima do professor português Vítor Manuel de Aguiar e Silva, publicada em 1967, o livro nacional mais destacado neste assunto foi $A$ criação literária (1965), de Massaud Moisés (1928-2018).

Esse panorama do ensino universitário, mais ou menos de 1930 a 1980, assinalado, num primeiro momento, pelo predomínio absoluto da história da literatura, depois caracterizado pela ascensão da teoria da literatura, até que esta disciplina viesse a assumir uma posição de destaque nos currículos, ambas apoiadas por materiais bibliográficos majoritariamente constituído pelos grandes tratados de história literária e por manuais de teoria da literatura, teria sua fisionomia profundamente alterada a partir da década final do século XX. Nessa altura, depois da depreciação da perspectiva historicista, entra em declínio também a teoria da literatura, e praticamente se aposentam os livros-textos que representavam o esteio principal da formação dos alunos, substituídos por materiais bibliográficos heterogêneos e fragmentários, basicamente compostos de estudos pontuais sobre temas do momento, frequentemente na forma de artigos, veiculados por periódicos acadêmicos especializados, ou então inseridos em livros de autoria coletiva, como capítulos.

As antologias, por sua vez, continuam a ser produzidas. Sua função, contudo, em relação ao propósito que as orientou no século XIX - demonstrar aos próprios brasileiros que o País dispunha de produção poética de alto nível, desde 
os tempos coloniais -, mudou. Tornaram-se elas instrumentos didáticos, inicialmente destinadas ao ensino de língua e literatura vernáculas em nível médio. A mais famosa delas - Antologia nacional, de Fausto Barreto (1852-1908) e Carlos de Laet (1847-1927) - constituiu uma espécie de elo entre os séculos XIX e XX, pois, publicada em 1895, teve quarenta e três edições, a última das quais em 1969. Outras antologias, porém, especialmente as de poesia, destinaram-se ou à divulgação de obras de poetas - caso daquelas organizadas por Manuel Bandeira (1886-1968), com a colaboração de Walmir Ayala (1933-1991): Apresentação da poesia brasileira (1946) e Antologia de poetas brasileiros, das fases colonial (1967), romântica (1937), parnasiana (1940), simbolista (1967) e moderna (1967) -, ou ao apoio do ensino universitário de literatura, sendo exemplos dessa categoria de publicações Presença da literatura portuguesa (1961), dirigida por Antônio Soares Amora, com a colaboração de Segismundo Spina (1921-2012) e Massaud Moisés, e Presença da literatura brasileira (1964), de Antônio Cândido (1918-2017) e José Aderaldo Castello (1921-2011).

A produção de edições cuidadas, outro aspecto da cultura literária brasileira que teve um início promissor no século XIX - sobretudo, como antes assinalamos, graças a Joaquim Norberto -, muito deixou a desejar nos séculos XX, sem sinais, até o presente, de que esse panorama se altere muito no XXI. Assim, mesmo obras fundamentais, como, entre muitas outras, as de Machado de Assis, permanecem aguardando um tratamento editorial de maior qualidade.

A crítica literária stricto sensu, isto é, a apreciação de obras literárias específicas - especialmente as recém-lançadas -, orientada para a emissão de juízos de valor estético, seguiu seu curso, servindo-se, à maneira do que já ocorrera no século XIX, sobretudo de jornais, veículos afinal apropriados para o seu propósito, que é difundir a produção literária junto a um público heterogêneo e não especializado. Nas primeiras décadas do século XX, essa crítica ocupava espaços generosos nesses veículos, e não faltaram nomes que alcançaram reputação de grandes críticos, pela regularidade das matérias que assinavam, como, por exemplo, João Ribeiro (1860-1934), Medeiros e Albuquerque (1867-1934), Agripino Grieco (1888-1973), Alceu Amoroso Lima (1893-1983), Humberto de Campos (1886-1934), Álvaro Lins (1912-1970), Wilson Martins (1921-2010), os quais, em 
geral, reuniam posteriormente em volumes seus escritos antes estampados nos jornais. Wilson Martins assim explicou esta prática:

\begin{abstract}
A crítica literária tem compromisso com a atualidade e a ambição da permanência: é por isso que os críticos reúnem periodicamente em volume os seus trabalhos, como capítulos virtuais da futura história da literatura, para o qual, em linguagem de ourivesaria, serviam de contraste, isto é, como índice de avaliação (Martins, 2005).
\end{abstract}

Esse tipo de crítica, de cunho impressionista - isto é, limitada à exposição das impressões de leitura dos críticos, sem qualquer compromisso com teorias ou métodos -, começou a perder espaço e influência por volta dos anos 1960, por pelo menos duas razões conjugadas.

Por um lado, a modernização da imprensa diária, pautada cada vez mais por objetividade, ligeireza e sintetismo, conduziu a alterações na própria diagramação tradicional dos jornais impressos, reduzindo os espaços das páginas, o que implicou o gradual encolhimento nos jornais de circulação diária das colunas de crítica, que hoje praticamente desapareceram, bem como a progressiva extinção dos chamados suplementos literários (cadernos especializados em literatura, geralmente anexos aos números de sábado ou domingo dos grandes jornais). No entanto, é importante assinalar que essa diminuição ou extinção dos espaços para a crítica literária não ocorreu só no âmbito desse tipo de crítica, mas também no de outras modalidades de práticas críticas (de teatro, artes plásticas, cinema, etc.). E se deu simultaneamente com a diminuição geral da própria mídia impressa, que incluiu desaparecimentos de veículos tradicionais, surgimento de novos e uma reformatação generalizada de sua apresentação e propósitos, inclusive para competir com publicações distribuídas gratuitamente em metrôs, lojas comerciais, hotéis e assemelhados, nas grandes cidades do Brasil - publicações, por sinal, bancadas integralmente por patrocinadores. Nesse modelo de mídia, se nem a cobertura de fatos relevantes para a maioria da população ganha espaço de análise mais desenvolvido, não se poderia esperar uma atenção especial para a crítica.

Por outro lado, no Brasil, a criação dos cursos superiores de letras produziu as condições para o desenvolvimento do que, um tanto impropriamente, foi chamado de crítica universitária, e cujo nome mais preciso deveria ser estudos 
literários, por tratar-se, na verdade, de um amálgama de disciplinas que, além de práticas críticas stricto sensu, compreende também história e teoria literárias.

Essa crítica universitária, nos anos 1950, movida por ânimo polêmico, procurou marcar diferença em relação ao que ela passou a rotular, pejorativamente, como crítica de rodapé (porque, nas origens, os artigos críticos ocupavam as partes inferiores das páginas dos jornais impressos, isto é, os rodapés), crítica jornalística ou crítica impressionista. Com isso, instituíram-se duas modalidades de crítica: uma exercida por leitores cultos não especializados, atuantes na imprensa, e outra por professores especialistas, regentes de disciplinas universitárias. Aquela, destinada ao chamado grande público dos jornais impressos, perdeu gradualmente seu espaço e prestígio, como vimos, a ponto de hoje estar virtualmente extinta; esta, circulante no meio acadêmico, e cujo impulso inicial deveu-se à implantação das faculdades de letras no País, encontra-se institucionalmente forte na atualidade, desde pelo menos a década de 1970, beneficiária que foi da criação de cursos de pós-graduação na área.

A história da literatura, por sua vez, manteve o vigor com que se apresentou no século XIX.

Do ponto de vista institucional, houve a consolidação de literatura brasileira e literatura portuguesa - construções conceituais historicistas, como se sabe, a exemplo dos demais campos configurados como literaturas nacionais -, que alcançaram o indiscutível status de principais disciplinas literárias, tanto do ensino médio como do universitário, situação que só começaria a alterar-se inicialmente a partir da década de 1960, com a admissão de teoria da literatura entre essas disciplinas, e, depois, desde mais ou menos o ano 2000, com certa queda de prestígio experimentada por literatura portuguesa.

Do ponto de vista das publicações, surgem importantes ensaios dedicados a definir o conceito de literatura brasileira, bem como, correlativamente, empenhados em propor categorias e métodos aptos para o estudo historiográfico das obras constitutivas do seu campo. Exemplificam essa vertente de ensaios: Uma interpretação da literatura brasileira (1943), de Vianna Moog (1906-1988); Introdução à literatura brasileira (1956), de Alceu Amoroso Lima; Conceito de literatura brasileira (1960), de Afrânio Coutinho (1911-2000). No entanto, Formação da literatura brasileira (1957), de Antônio Cândido, será sem dúvida o mais influente 
deles, a ponto de, embora limitado a tratar de apenas duas épocas históricas - 0 arcadismo e o romantismo -, ser tomado como uma história integral da cultura literária do País.

Não faltaram, porém, obras com essa proposição, as quais, no curso do século $X X$, deram sequência à trilha aberta no Oitocentos, cujo ponto culminante, como vimos, foi a História da literatura brasileira, de Sílvio Romero. Alguns desses títulos se mantiveram bastante conformes às matrizes oitocentistas do gênero, como a História da literatura brasileira, de José Veríssimo, publicada em 1916, e a Pequena história da literatura brasileira, de Ronald de Carvalho (1893-1935), datada de 1919. Outros projetos, contudo, propuseram reconcepções da historiografia das letras nacionais, a partir de novos e diversificados fundamentos. Estão nesse caso: a História da literatura brasileira (1938), de Nélson Werneck Sodré (1911-1999); A literatura no Brasil (1968-1971), obra de autoria coletiva dirigida por Afrânio Coutinho; os seis volumes da Série "A literatura brasileira", da Coleção "Roteiros das grandes literaturas" - Manifestações literárias da era colonial (1962), de José Aderaldo Castello; O romantismo (1967), de Antônio Soares Amora; O realismo (1963), de João Pacheco (1919-1966); O simbolismo (1966), de Massaud Moisés; O pré-modernismo (1966), de Alfredo Bosi; O modernismo (1965), de Wilson Martins (1921-2010) -; História concisa da literatura brasileira (1970), de Alfredo Bosi; De Anchieta a Euclides (1977), de José Guilherme Merquior (1941-191); História da literatura brasileira (1983-1989), de Massaud Moisés; A literatura brasileira: origens e unidade (1999), de José Aderaldo Castello (1921-2011).

No entanto, os grandes tratados de história da literatura brasileira, constitutivos, segundo antes assinalamos, não só de um gênero acadêmico, mas também de uma instituição nacional - à medida que definiram matéria de ensino obrigatória, nos níveis médio e universitário -, já davam sinais de exaustão por volta da década de 1970. Desse modo, a História da literatura brasileira, de Massaud Moisés, decorridos cem anos após a publicação da obra-marco homônima de Sílvio Romero, parece ter sido um dos últimos da espécie, pois, embora tenham sido posteriormente produzidas obras de viés histórico sobre a literatura brasileira, não há indícios de que esse gênero-instituição, pelo menos do modo como era produzido no passado, venha a ser revitalizado no presente. 
Esse fato, porém, constitui somente um aspecto de mudança mais ampla no cenário dos estudos literários no Brasil, observável desde o final do século passado e configurado mais nitidamente nestas primeiras duas décadas do século XXI.

\section{3}

A crítica que circulava nas edições impressas dos grandes jornais, como vimos, praticamente desapareceu, mas ainda sobrevive nesses mesmos veículos, em suas edições digitais. Alternativamente, uma crítica veiculada em meio digital, sob formas diversas (magazines, periódicos, sítios, blogs, etc.), se faz presente de modo cada vez mais intensa.

A chamada crítica universitária, por sua vez, teve os seus componentes tradicionais significativamente alterados. Entre as disciplinas constituídas por literaturas nacionais, literatura brasileira manteve sua posição de destaque, ao passo que literatura portuguesa perdeu bastante espaço, e as literaturas africanas de língua portuguesa estão em ascensão, embora com status curricular ainda incipiente nas universidades, o mesmo ocorrendo com literatura comparada, esta última principalmente em nível de pós-graduação. Diferentemente de momentos anteriores, as obras que compõem todas essas literaturas disciplinarizadas não vêm sendo mais tratadas apenas como integrantes de um sistema orientado para a realização plena do caráter nacional, ou como artefatos verbais densos e autorreferenciais. Frequentemente, são estudadas também em suas relações com outras formações discursivas - não necessariamente literárias -, e nessa mudança de abordagem observa-se uma substituição de paradigmas conceituais: em vez dos fundamentos fornecidos pela história e pela teoria literárias, a referência passa a ser uma ideia expandida de literatura, que inclui elementos antes excluídos, fazendo com que a literatura perca os traços que, na perspectiva dos séculos XIX e XX, lhe imprimiam certa marca peculiar.

Esse estado de coisas parece estar sendo cada vez mais institucionalizado, muitas vezes apresentando-se como congruente com movimentos sociais de proposição emancipatória, como o feminismo e a luta de grupos étnicos minoritários. Nesse sentido, basta que se verifiquem as reformas curriculares dos 
cursos de graduação, com apoio de legislação federal, ora em processo no Brasil, que têm por objetivo sintonizar os cursos de letras com essas novas agendas, bem como a expansão e a consolidação de vários programas de pós-graduação em estudos literários.

Tal ideia expandida de literatura, para o bem ou para o mal, também tem sido discutida em associações profissionais acadêmicas, como a Associação Nacional de Pós-Graduação e Pesquisa em Letras e Linguística - ANPOLL - e a Associação Brasileira de Literatura Comparada - ABRALIC -, fundadas respectivamente em 1984 e 1986.

Uma avaliação desse cenário comporta pelo menos dois aspectos. Por um lado, é indiscutível a pertinência histórica de toda essa discussão, pois nem a crítica pode ser separada de forma absoluta das situações complexas em que se produz e se usa, nem o crítico é um pensador isolado, uma ilha em si mesmo. De fato, ambos enraízam-se em comunidades históricas, nas quais o mundo sempre já se encontra investido e penetrado de sentidos previamente articulados, que dão continuidade a relações socialmente elaboradas. Por outro lado, há também um risco: o de que os estudos literários percam por completo a sua especificidade, se forem diluídos em elementos e métodos de outros campos de saber, vendo-se, assim, privados das condições para se legitimarem, tanto no plano epistemológico como no político-acadêmico.

\section{Referências}

MARTINS, Wilson. Sobre a crítica. Originalmente publicado em JBonline, 03/09/2005.

ROMERO, Sílvio. João do Rio entrevista Sílvio Romero [1907]. Bula Revista. Disponível em: http://acervo.revistabula.com/posts/entrevistas/joao-do-rioentrevista-silvio-romero Acesso em: 21 out. 2019. 